\title{
COSMOGENIC RADIOCARBON AND CYCLICAL NATURAL PROCESSES
}

\author{
VALENTIN DERGACHEV
}

A. F. Ioffe Physico-Technical Institute, Russian Academy of Sciences, Polytechnicheskaya 26
St. Petersburg 194021 Russia

and

VLADIMIR CHISTYAKOV

Ussuriiysk Astrophysical Observatory, Russian Academy of Sciences, Ussuriiysk-19

Primorskiy Krai 692519 Russia

\begin{abstract}
We investigated relations among solar activity, climate and cosmogenic radiocarbon in a time series of various astrophysical, geophysical, archaeological and historical data. We studied records of tree-ring thickness, aurora borealis, the catalog of visible sunspots, sedimentary deposits from lakes and oceans, global glacial advance and retreat chronology, polar ice cores and human migrations. In these data, we searched for evidence of medium- and long-term solar cycles. Application of different spectral techniques to the atmospheric ${ }^{14} \mathrm{C}$ concentration time series indicates the existence of spectral lines at a few dominant periodicities ranging from $11 \mathrm{yr}$ to ca. $2 \mathrm{ka}$. Different laboratories have confirmed the presence of the ca. 210and 2000 -yr spectral features in long ${ }^{14} \mathrm{C}$ series in tree rings. The ca. $210-\mathrm{yr}{ }^{14} \mathrm{C}$ cycle is probably caused by heliomagnetic modulation of the cosmic-ray flux. The extrema of both the ca. $210-\mathrm{yr}{ }^{14} \mathrm{C}$ period and solar activity correlate with the cold and warm epochs of global climate, at least for the past millennium, and this correlation has the correct sign. The periods of low solar activity are well correlated with the Little Ice Ages. The cause of the $c a .2 \mathrm{ka}{ }^{14} \mathrm{C}$ period is, as yet, uncertain, but evidence from the analyses of various natural records shows that it could have a solar origin. In this study, we obtained powerful manifestations of solar activity and climate warming epochs at ca. 1500, 3800, 6100, 8200, 10,500 and 12,600 BP. A similar feature occurs in epochs of minimum amplitude in the ${ }^{14} \mathrm{C}$ content in tree rings. Thus, solar activity may affect both the ${ }^{14} \mathrm{C}$ content in the Earth's atmosphere and climate.
\end{abstract}

\section{INTRODUCTION}

Detailed studies of radiocarbon content in tree rings provide a unique data set for precise ${ }^{14} \mathrm{C}$ age calibration of materials formed in isotopic equilibrium with atmospheric $\mathrm{CO}_{2}$. We focus here on the Holocene, i.e., the last $10 \mathrm{ka}$. The beginning of this interval corresponds to an uncertain calendar age, because the observed atmospheric calibration curve flattens near $10 \mathrm{ka}$. De Vries (1958) was the first to demonstrate evidence for secular variations of natural ${ }^{14} \mathrm{C}$ content in the Earth's atmosphere. Willis, Tauber and Münnich (1960) showed that atmospheric ${ }^{14} \mathrm{C}$ activity appears to be cyclical, with a period of $c a .200 \mathrm{yr}$ over the past $1300 \mathrm{yr}$. Suess (1965) showed that tree rings contain quantitatively short-term wiggles and secular variations in the content of cosmogenically produced ${ }^{14} \mathrm{C}$ in the atmosphere. However, it has long been assumed that the measured short-term fluctuations, with amplitudes of $<1 \%$ in the natural ${ }^{14} \mathrm{C}$ concentration, represent random variations. The precise measurements needed to define the short-term fluctuations induced by solar activity will require high precision as well as sensitivity (Damon et al. 1978). Accuracies of the ${ }^{14} \mathrm{C}$ measurements were insufficient to demonstrate the irrefutable existence of the wiggles. These earlier measurements of ${ }^{14} \mathrm{C}$ concentration were subject to large laboratory uncertainties and statistical fluctuations. After numerous interlaboratory checks on measurements of ${ }^{14} \mathrm{C}$ content in identical samples in different countries, methodological flaws were largely identified and eliminated. One must be cautious in separating and interpreting short-term cyclical fluctuations from the ${ }^{14} \mathrm{C}$ content, because spectral analysis of series of data with high noise components raises the question of extracting the true harmonics from the spurious spectral lines. However, reliable experimental material now accumulated in the ${ }^{14} \mathrm{C}$ content in samples of known age suggests the possibility of selectively separating, from the ${ }^{14} \mathrm{C}$ data, information generated by a complex of interfering astrophysical and geophysical processes. 
High-precision measurements of the ${ }^{14} \mathrm{C}$ content in tree rings of known age to study causes of changes in atmospheric ${ }^{14} \mathrm{C}$ concentrations in the past began ca. $20 \mathrm{yr}$ ago in different world laboratories. Many measurements have been made, both of continuous annual series of tree-ring samples, covering time scales from decades to hundreds of years, and of continuous samples of decadal or bidecadal rings, spanning several millennia (see, e.g., Stuiver and Kra 1986; Stuiver and Becker 1986; Pearson et al. 1986). ${ }^{14} \mathrm{C}$ measurements show not only three types of fluctuations: short-term (years to several decades); medium-term (decades to several hundreds of years); and long-term (thousands of years), but also their details. These fluctuations are characterized by a different amplitude of change in the ${ }^{14} \mathrm{C}$ concentration: fractions of a percentage, $1-2 \%$ and as much as $11 \%$, respectively, for short-, medium- and long-term fluctuations (see Fig. 1, Stuiver and Kra 1986).

We examine here the medium-term variations of a period of $c a .210 \mathrm{yr}$ and long-term variations of a period ca. $2 \mathrm{ka}$ in terrestrial ${ }^{14} \mathrm{C}$ concentration, and the relation between the ${ }^{14} \mathrm{C}$ record and some cyclical natural processes.

\section{MANIFESTATION OF MEDIUM- AND LONG-TERM ${ }^{14}$ C FLUCTUATIONS}

By examining ${ }^{14} \mathrm{C}$ content, one is able to draw important conclusions about the ${ }^{14} \mathrm{C}$ activity level in wood samples of known age. First, it is important to note Suess' (1978) experimental data that extended to $c a .7 \mathrm{ka}$ BP from which he plotted his calibration curve. A characteristic feature of these data is the almost identical uncertainty in all the measurements (ca. 0.4\%). Admittedly, considerable gaps exist in his series at different intervals. At the University of Arizona, Damon et al. (1980) compiled $>1200$ determinations of ${ }^{14} \mathrm{C}$ activity in blocks of rings of bristlecone pine and giant sequoias extending beyond $7 \mathrm{ka} \mathrm{BP}$, in a compendium of results from various laboratories (Klein et al. 1980).

High-precision ${ }^{14} \mathrm{C}$ measurements of dendrochronologically dated wood samples, each covering 10 yr, are now available for AD 1950-6000 BC (Stuiver and Becker 1993). The U.S. bristlecone pine and the German oak chronologies covering the last $9150 \mathrm{cal}$ yr (Stuiver, Pearson and Braziunas 1986) have recently been extended to $c a .11,400$ BP (Kromer and Becker 1993).

One can observe the physical manifestation of the ca. 210-yr cycle in the relative deviations of the measured ${ }^{14} \mathrm{C}$ activities upon removal of the long-term trend. Figure 1 shows these $c a .210-\mathrm{yr}{ }^{14} \mathrm{C}$ concentration oscillations during the last two millennia derived from several results summarized in Stuiver and Kra (1986). Note that the magnitude of these ${ }^{14} \mathrm{C}$ content oscillations are sensitive to geomagnetic field intensity changes. Most data on the behavior of the intensity of the archaeomagnetic field indicate that values of the dipole moment peaked 2000-2500 yr ago (e.g., see Merrill and McElhinny 1983).

The mathematical manifestation of this 210 -yr period can be obtained by applying statistical techniques of time series analysis. The classical method analysis, Fourier harmonic and BlackmanTukey spectral analysis, have been applied first to the cosmogenic ${ }^{14} \mathrm{C}$ data. Using Fourier analysis of the ${ }^{14} \mathrm{C}$ content variations, Houtermans (1971) reported the $c a$. 200- and 2000-yr periodicities. The Fourier spectrum of ${ }^{14} \mathrm{C}$ variations during the period $5300 \mathrm{BC}-\mathrm{AD} 150$ in bristlecone pine samples measured in La Jolla showed a conspicuous spectral line at ca. $200 \mathrm{yr}$ (Suess 1980). Neftel, Oeschger and Suess (1981), and even more conclusively, Sonett and Suess (1984) confirmed this period in the La Jolla spectrum.

Figure 2 shows changes in the ${ }^{14} \mathrm{C}$ content based on tree-ring data, ranging back to $c a .11,400 \mathrm{BP}$. Note that the major anomalies occur every ca. $2 \mathrm{ka}$ and represent the strongest feature in the ${ }^{14} \mathrm{C}$ record on a long-term scale. This feature becomes more pronounced when filtering the raw data, 


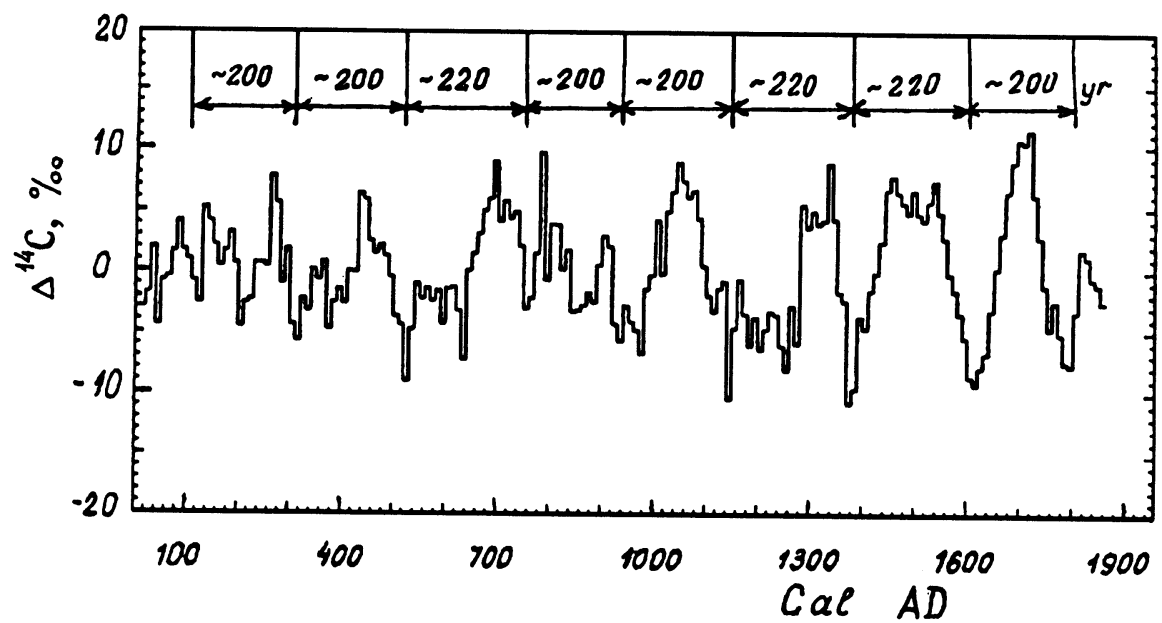

Fig. 1. Changes in ${ }^{14} \mathrm{C}$ concentration relative to an average value (Stuiver and $\mathrm{Kra}$ 1986). The intervals indicate a repetitive pattern of medium ${ }^{14} \mathrm{C}$ oscillation.

according to Dergachev (1992). The maximum amplitude of the large-scale oscillations occurs at $c a$. $450,2700,4950,7200$ and $9450 \mathrm{BP}$, and minimum amplitude of these oscillations occurs at ca. 550, 3800,6100 and $8300 \mathrm{BP}$. Four larger medium-term fluctuations (Hallstattzeit maxima) occur every $2100-2400 \mathrm{yr}$ in the ${ }^{14} \mathrm{C}$ concentration for the past seven millennia, based on compendia of results from various laboratories (Damon, Cheng and Linick 1989; Damon and Sonett 1992). These maxima occur at 250-450, 2700, 4870 and $7150 \mathrm{BP}$. The strongest feature in the ${ }^{14} \mathrm{C}$ record with the long period of $c a .2$ ka was extracted from La Jolla data (Suess 1978) after removing the long-term sinu-

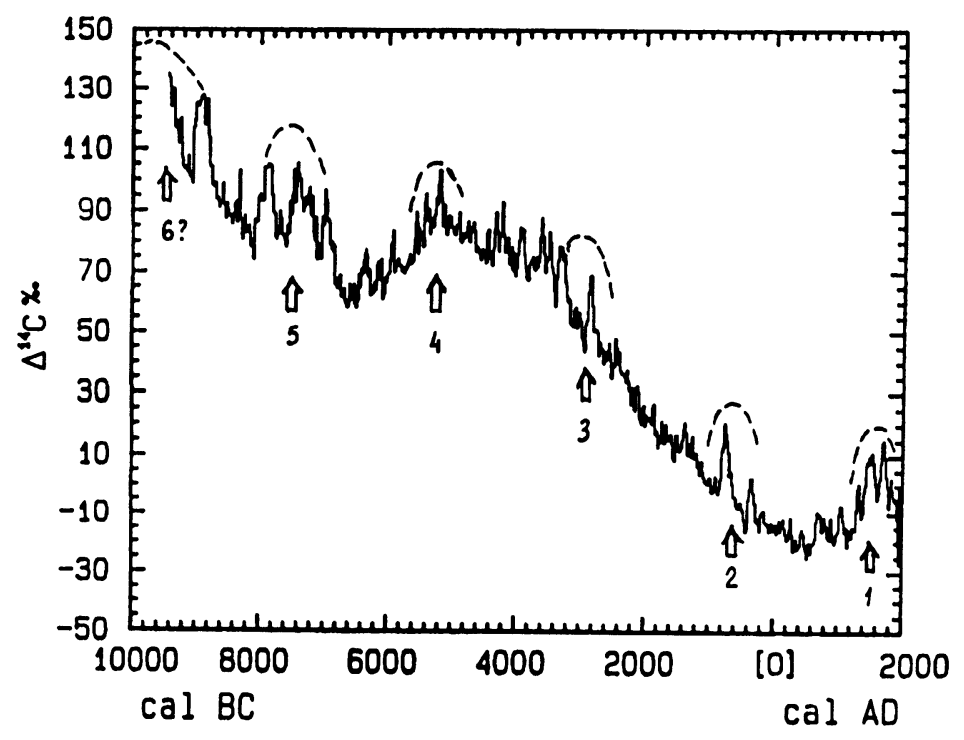

Fig. 2. Bidecadal values of ${ }^{14} \mathrm{C}$ content changes to ca. $11,400 \mathrm{BP}$ (Stuiver and Reimer 1993). Arrows show anomalously high values of ${ }^{14} \mathrm{C}$ content. 
soidal trend curve with a period of $c a .10 \mathrm{ka}$ (Dergachev and Akhmetkereev 1990). The long-term trend can be determined in various ways (e.g., sine equations, moving averages, splines).

Much fruitful research has been done in recent years in applying statistical techniques to ${ }^{14} \mathrm{C}$ data. High-precision ${ }^{14} \mathrm{C}$ data from tree rings have a well-defined spectrum, consisting of numerous periods of detrended data ranging from $11 \mathrm{yr}$ to $c a .2400 \mathrm{yr}$. After Houtermans (1971), who reported a periodicity of $c a .2 \mathrm{ka}$, this large-scale variation of terrestrial ${ }^{14} \mathrm{C}$ was established by analyzing the spectral characteristics of the high-precision data with different techniques of time series analysis (e.g., Damon, Cheng and Linick 1989; Sonett and Finney 1990). At present, most experimental workers are not skeptical about the existence of periodicities in the natural ${ }^{14} \mathrm{C}$ content, and meaningful spectral lines at several periods in the ${ }^{14} \mathrm{C}$ sequences are not widely accepted. These periodic occurrences constitute an important source of scientific information.

\section{A LINK BETWEEN CYCLICITY OF ${ }^{14} \mathrm{C}$ AND FLUCTUATIONS OF SOLAR-TERRESTRIAL PHENOMENA}

\section{The 210-Year Period}

Let us observe the appearance of the ca. 210-yr period in various natural processes. The Maunder, Wolf and Spörer minima of solar activity are well-documented periods, separated by the ca. 200-yr intervals. Schove (1955) was among the first to observe the 210-yr cycle with the naked eye. He showed that the aurorae are more numerous in the even centuries than in the odd centuries. Chistyakov (1985) observed less solar activity during the odd 17th century than in the even 16th century. $\mathrm{Xu}$ (1990) found clear evidence of the 210-yr cycle in the historical solar record of ancient China.

The 200-yr trend is being documented on a global scale. Alexeev (1987) determined the variations for periods of $10.5 \pm 0.5 \mathrm{yr}, 85 \pm 10 \mathrm{yr}$ and $220 \pm 20 \mathrm{yr}$ in meteorite falls (although causally related correlations with solar variability are not evident). In his analysis of the rate of change of the angle of geomagnetic field direction, using contemporary and historical archaeomagnetic data, Tarling (1988) showed the periodicity to be ca. $200 \mathrm{yr}$. Goncharov (1993) showed that the invasions of great nomadic tribes from the Central Asian Steppe into agricultural regions of Europe, China and South Asia from the 4th to the 16th centuries were connected with the 210-yr cycle. These invasions occurred in middle latitudes after a dip in solar activity. Castagnoli et al. (1991) reported that the spectral analysis of three carbonate profiles from the Ionian Sea showed periodicities similar to those detected in the ${ }^{14} \mathrm{C}$ spectra. An important group is a triplet at $206 \mathrm{yr}$, amplitude-modulated of 2000 yr. High-precision ${ }^{14} \mathrm{C}$ data are now well established for most of the Holocene, where medium-term ${ }^{14} \mathrm{C}$ variation is attributed to changes in the ${ }^{14} \mathrm{C}$ production rate.

Ribes et al. (1990) proposed a simple model describing the convective processes at the time of low sunspot activity, and estimated the change of solar luminosity through the 11-yr and longer cycles, such as the Maunder minimum. With this model, the mean variation of the solar constant over several decades could cause changes of $0.5 \%$. The model, then, is a plausible physical mechanism linking the Maunder minimum to the Little Ice Age and to changes in solar activity.

Most of the observed variability of atmospheric ${ }^{14} \mathrm{C}$ concentration of at least the last $c a .11,000 \mathrm{cal}$ yr can be attributed to helio- and geomagnetic modulation of the ${ }^{14} \mathrm{C}$ production rate induced by the cosmic-ray flux. The influence of glacial-interglacial climate change on atmospheric ${ }^{14} \mathrm{C}$ concentration had a secondary effect (Akhmetkereev and Dergachev 1981). Stuiver and Braziunas (1993) also showed that the differences among glacial, deglacial and interglacial conditions had only secondary effects, as follows from two facts: 1 ) the model-derived ${ }^{14} \mathrm{C}$ production history agrees with the ${ }^{14} \mathrm{C}$ rate derived from documented changes in the geomagnetic field over the past $30 \mathrm{ka}$; and 2) the global-scale ${ }^{14} \mathrm{C}$ reservoirs respond relatively quickly to changes in ocean mixing processes, such 
that the new atmospheric ${ }^{14} \mathrm{C}$ level will have recovered after ca. $2 \mathrm{ka}$ (ocean turnover time). But relatively quick changes in ocean exchange between the mixed layer and deep sea could cause rather large changes in ${ }^{14} \mathrm{C}$ concentration. ${ }^{1}$ Major changes in the rate of deep-ocean ventilation occurred prior to $12,500 \mathrm{BP}$.

\section{The 2000-Year Period}

It is difficult to analyze numerous time series of natural data containing information on the 2 ka cycle. Bray (1968) detected the 2 ka wave in glacial advances of the 14th-18th and 4th-7th centuries BC. He associated them with depressions of solar activity. The appearance of giant peaks in 1375 and $1328 \mathrm{BC}$ as well as in $\mathrm{AD} 1185$ and 1239 (from the historical records of solar eclipses) indicates the extraordinary power of phenomena on the Sun (Chistyakov 1991). This example is direct evidence of the existence of the $2 \mathrm{ka}$ cycle in the solar processes.

Apart from the transitions from glacial to interglacial, the 2 ka period is fixed in numerous terrestrial examples of climate change. By studying Barbados corals, Bard et al. (1990) established two rises of ocean level at $c a .12,300$ and 10,000 BP. These results agree with epochs of ${ }^{14} \mathrm{C}$ concentration minima. From studies of the ocean sediments off the coast of Portugal, Bard et al. (1989) determined a significant rise in ocean level from 14,500-13,500 BP. Two warm periods in Scotland, England and Ireland ca. 13 and $10 \mathrm{ka} \mathrm{BP}$ were documented by Atkinson, Briffa and Coope (1987). Chappelar $e t$ al. (1990) found distinct oscillations of methane in air bubbles of ice cores from the Vostok station at 13 and $10 \mathrm{ka} \mathrm{BP}$. The methane concentration minimum occurred from 12-11 ka BP, corresponding to the cold period in the Younger Dryas.

Both thermoluminescence determinations on fine-grained sediment and ${ }^{14} \mathrm{C}$ determinations on various organic fractions of paleosols from the profile of the Loess Plateau in central China (Zhou et al. 1992) indicate a weakened summer monsoon during the last glacial maximum followed by strengthening of the summer monsoon, beginning $\mathrm{ca} .13 \mathrm{ka} \mathrm{BP}$. The next increase of Asian summer monsoon circulation began from ca. 10,200 BP. Hertelendi, Sümegi and Szöör (1992) reconstructed the climate of the Great Hungarian Plain based on mollusk fauna and isotope geochemical data from 7-32 $\mathrm{ka} \mathrm{BP}$. The warmest climates with high July temperatures occurred ca. 8500, 12,500 and 17,000 BP. Comparing these paleotemperatures with temperatures of existing climate curves shows the same climate periods.

The maxima and minima of extreme changes of mean annual ocean temperatures in the Atlantic during the past 16 ka can be estimated from Arabadzhi's (1988) results. Maxima appear at 15,600 , $13,300,11,100$ and $6200,4100,1050 \mathrm{BP}$. Minima are at 14,600,12,800,10,500 and 5100, 2800, 400 BP. From 11,100-6200 BP (for maxima) and 10,500-5100 BP (for minima), the temperature curve reaches an extremely high peak; it seems that these intervals cover two fluctuations within a ca. $2 \mathrm{ka}$ period. The mean interval between temperature extrema is $2400 \pm 230$ (12 events).

Using pollen data from France (Guiot et al. 1989) for the past $140 \mathrm{ka}$, Dergachev and Chistyakov (1992a) compiled a series of temperature maxima (estimated from a theoretical series of temperatures of $c a .2 \mathrm{ka}$ ). The temperature maxima of this series coincides well with the ocean temperature maxima in the Atlantic and with the low minima of the ${ }^{14} \mathrm{C}$ content. Pestiaux, Berger and Duplessy (1987) also found these quasiperiodicities in the ${ }^{18} \mathrm{O}$ record in ice cores and foraminifera from ocean cores. Secular climatic variations affect all living things. Archaeology offers important evidence of

\footnotetext{
${ }^{1}$ Purely oceanic forcing is difficult to explain, involving exchange processes and complex ocean chemistry. Consideration of this problem is beyond the scope of this paper.
} 
climate change and durations of both favorable and unfavorable intervals for human settlements. Dergachev and Chistyakov (1993) found that the most northern Paleolithic and Neolithic settlements, between which the typical period of abandonment averaged $c a .2 \mathrm{ka}$, correlate well with the warming periods.

\section{ON THE STRUCTURE OF THE 2000-YEAR CYCLE}

We established that the interval of the ca. 2 ka cycle includes alternating warm and cold periods (little climatic optima and little ice ages). We observed these alternations before, during and after glacial periods (Dergachev and Chistyakov 1992b). Increased solar activity is accompanied by climate warming and vice versa. Weak and strong peaks (several decades' duration) are superimposed on the $2 \mathrm{ka}$ trend in the variations of $\delta^{18} \mathrm{O}$ concentration (Johnsen, Dansgaard and Clausen 1970). Oscillations in $\delta^{18} \mathrm{O}$ and $\Delta^{14} \mathrm{C}$ correlate well during the interval from AD 13001900 (Schove 1981). Eddy (1976) noted that two episodes of strongly decreasing solar activity (the Maunder and Spörer minima) were preceded by the medieval maximum of solar activity. These episodes correspond to the last Little Ice Age and the Little Climatic Optimum.

From the mean temperature change curve of the Atlantic Ocean (as discussed above), one can estimate the mean interval between two extrema, which is $T=2400 \pm 200 \mathrm{yr}$. Minima appear $(900 \pm 300$ yr) $(\Delta T)$ after maxima. We propose that the durations of the warm and cold phases equal $\Delta T$ and the duration of the quiet phase is $\delta \mathrm{T} \sim 800-1300 \mathrm{yr}$.

It is well known that climate warming is accompanied by transgressions of the World Ocean and regressions of lakes and seas with closed basins. From the data of Kalinin, Breslav and Klige (1975) on level fluctuations of the World Ocean and Caspian Sea, Dergachev and Chistyakov (1993) estimated the mean intervals of the 2 ka cycle structure: $\mathrm{T}=2500 \pm 300, \Delta \mathrm{T}=700 \pm 200, \delta \mathrm{T}=1100 \pm$ 500 (Fig. 3). The analysis of detailed data on the sharp switch-over of warm and cold climate periods and the influences of these changes on human life for the last millennia enable us to represent the structure of the 2 ka solar and climatic cycle. Figure 3 shows these three phases: 1$)$ the active $(+)$ phase with a high level of solar activity and the little climatic optimum; 2 ) the depression (-) phase with a decrease in solar activity like the Maunder and Spörer minima and the Little Ice Age. This phase follows the active phase with the time shift of $\Delta T ; 3$ ) the quiet phase $\delta \mathrm{T}$. Chistyakov (1993) estimated the duration of this phase as $\delta \mathrm{T} \geq 800 \mathrm{yr}$. Reliable ${ }^{14} \mathrm{C}$ data enable us to trace both the separate elements in and the whole structure of the 2 ka cycle.

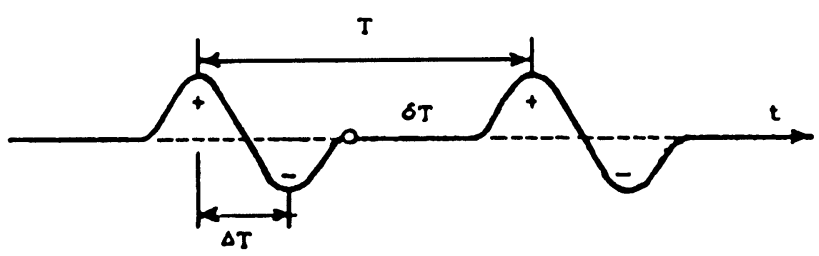

Fig. 3. The structure of the $c a$. 2400 -yr cycle of solar activity and climate. $\mathrm{T}=$ full period; $\Delta \mathrm{T}=$ time from the maximum active phase to the minimum depression phase; $\delta \mathrm{T}=$ quiet phase; $\mathrm{t}=$ current time; $\mathrm{O}=$ the present.

\section{Conclusion}

The last dip of solar activity (the Maunder minimum) ended at the start of the 18th century. In subsequent centuries, solar activity increased and the climate warmed. The strongest solar cycle was the 19 th cycle with the sunspot maxima in 1957 . In subsequent cycles, activity decreased. The last minimum of the 210 -yr period in solar activity occurred at the end of the 19th century. The maximum 
of this cycle should occur in the early 21st century. Climate warming accompanies increasing solar activity. Multicentury increases of solar activity are no longer possible. The present levels of solar activity and climate correspond to the quiet phase, $\delta \mathrm{T}$, which will continue for several centuries. We found the possible fluctuations of the Sun's luminosity during the maximum of its activity to be small (Dergachev and Chistyakov 1992a). Thus, we conclude that the Sun is a stable system. Much effort has been made to find solar cyclicity in the geophysical records. Evidence for a statistically significant 11(22)-, ca. 210- and $c a$. 2000-yr periodicity in various terrestrial indices is increasing.

\section{REFERENCES}

Akhmetkereev, S. Kh. and Dergachev, V. A. 1981 Simulation of the influence of some climatic factors on the ${ }^{14} \mathrm{C}$ content in the Earth's atmosphere. Isvestiya Akademii Nauk SSSR. Seriya Fizicheskaya 45: 1189-1194 (in Russian).

Alexeev, V. A. 1987 Statistics of meteorite falls. Lunar and Planetary Sciences 18:15-16 (in Russian).

Arabadzhi, M. S. 1988 In the Interior of the Blue Continent. Moscow, Nedra: $142 \mathrm{p}$.

Atkinson, T. C., Briffa, K. R. and Coope, C. R. 1987 Seasonal temperatures in Britain during the past 22,000 yr, reconstructed using beetle remains. Nature 325 : 587-592.

Bard, E., Fairbanks, R., Arnold, M., Maurice, P., Moyes, J. and Duplessy, J.-C. 1989 Sea level estimates during the last deglaciation based on $\delta^{18} \mathrm{O}$ accelerator mass spectrometry ${ }^{14} \mathrm{C}$ ages measured in Globigerina bulloides. Quaternary Research 31(3): 381-391.

Bard, E., Hamelin, B., Fairbanks, R. G. and Zindler, A. 1990 Calibration of the ${ }^{14} \mathrm{C}$ timescale over the past 30,000 yr using mass-spectrometric U-Th ages from Barbados corals. Nature 345: 405-410.

Bray, J. R. 1968 Glacial and solar activity since the fifth century BC and the solar cycle. Nature 220: 672-674.

Castagnoli, G. C., Bonino, G., Provenzale, A. and Serio, M. 1991 Climatic change and radiocarbon modulation. In Proceedings of the 22nd International Cosmic Ray Conference. Dublin 3: 709-712.

Chappelar, J., Barnola, J. M., Raynaud, D., Korotkevich, Y. S. and Lorius, C. 1990 Ice-core record of atmospheric methane over the past 160,000 years. Nature 345: 127-131.

Chistyakov, V. F. 1985 The anomalies of solar activity. Solnechnye Dannye 12: 51-57 (in Russian).

1991 Chromosphere and prominences in ancient eclipse data. Solnechnye Dannye 12: 73-78 (in Russian).

1993 The solar cycle with the duration of $c a .2400$ years. Solnechnye Dannye 1:81-85 (in Russian).

Damon, P. E., Cheng, S. and Linick, T. W. 1989 Fine and hyperfine structure in the spectrum of secular variations of atmospheric ${ }^{14} \mathrm{C}$. In Long, A. Kra, R. S. and Srdox, D., eds., Proceedings of the 13th International ${ }^{14} \mathrm{C}$ Conference. Radiocarbon 31(3): 704-718.

Damon, P. E., Lerman, J. C. and Long, A. 1979 Temporal fluctuations of atmospheric ${ }^{14} \mathrm{C}$ : Causal factors and implications. Annual Reviews of Earth and Planetary Sciences 6: 457-494.

Damon, P. E., Lerman, J. C., Long, A., Bannister, B., Klein, J., and Linick, T. W. 1980 Report on the Workshop on Calibration of the Radiocarbon Time Scale. In Stuiver, M. and Kra, R., eds. Proceedings of the 10th International ${ }^{14} \mathrm{C}$ Conference. Radiocarbon 22(3): 947-949.

Damon, P. E. and Sonett, C. P. 1992 Solar and terrestrial components of the atmospheric ${ }^{14} \mathrm{C}$ variation spectrum. In Sonett, C. P., Giampapa, M. S. and Matthews, M. S., eds., The Sun in Time. Tucson, The University of Arizona Press: 360-388.

Dergachev, V. A. 1992 On fixation of the extreme states of past solar activity by cosmogenic isotopes. In Vitinsky, Yu. I., Dergachev, V. A., Kuklin, G. V., eds., Spatial-Time Aspects of Solar Activity. St. Petersburg, Ioffe Physico-Technical Institute: 171-180 (in Russian).

Dergachev, V. A. and Akhmetkereev, S. Kh. 1990 On the nature of supersecular variations of radiocarbon in the Earth's atmosphere. In Protheroe, R. J., ed., Conference Papers of the 21st International Cosmic Ray Conference. Adelaide, Australia, Department of Physics and Mathematical Physics, the University of Adeliade 7: 128-131.

Dergachev, V. A. and Chistyakov, V. F. (ms.) 1992a On solar activity and climate at a border of the Pleistocene and the Holocene. Preprint of Ioffe Physico-Technical Institute, No.1586, St. Petersburg: 27 p. (in Russian). 1992b On the powerful manifestations of solar activity during the end of the Pleistocene and the beginning of the Holocene. Solnechnye Dannye 2: 73-79 (in Russian).

1993 210- and 2400-year solar cycles and climate changes. In Vitinsky, Yu. I., Dergachev, V. A., Kuklin, G. V. eds., Solar Cycle. St. Petersburg, Ioffe PhysicoTechnical Institute: 112-130 (in Russian).

de Vries, H. 1958 Variation in concentration of radiocarbon with time and location on earth. In Koninklijke Nederlandse Academie van Wetenschappen B 61: 94-102.

Eddy, J. A. 1976 The Maunder minimum. Science 192: 1189-1202.

Goncharov, G. A. (ms.) 1993 Asian nomad invasion and solar cycles. Paper presented at the International Symposium on Relations of Biological and Physicochemical Processes with Solar Activity and other Environ- 
mental Factors, Pushchino, Russia, 27 September-1 October.

Guiot, J., Pons, A., de Beaulieu, J. L. and Reille, M. 1989 A 140,000-year continental climate reconstruction from two European pollen records. Nature 338: 309-313.

Hertelendi, E., Sümegi, P. and Szoor, F. 1992 Geochronologic and paleoclimatic characterization of Quaternary sediments in the Great Hungarian Plain. In Long, A. and Kra, R. S., eds., Proceedings of the 14th International ${ }^{14} \mathrm{C}$ Conference. Radiocarbon 34(3): 833-839.

Houtermans, J. C. (ms.) 1971 Geophysical Interpretation of Bristlecone Pine Radiocarbon Measurements Using a Method of Fourier Analysis of Unequally Spaced Data. Ph.D. dissertation, University of Bern.

Johnsen, S. J., Dansgaard, W. and Clausen, H. B. 1970 Climatic oscillations 1200-2000 AD. Nature 227: 482-483.

Kalinin, G. P., Breslav, E. I.and Klige, R. K. 1975 Some questions of the contemporary ocean level. In Kalinin, G. P. and Klige, R. K., eds., World Ocean Level Fluctuations and Geomorphology Problems. Moscow, Nauka: 5-12 (in Russian).

Klein, J., Lerman, J. C., Damon, P. E. and Linick, T. Radiocarbon concentration in the atmosphere: 8000 -year record of variations in tree rings. In Stuiver, $M$. and $\mathrm{Kra}, \mathrm{R}$. S., Proceedings of the 10th International ${ }^{14} \mathrm{C}$ Conference. Radiocarbon 22(3): 950-961.

Kromer, B. and Becker, B. 1993 German oak and pine ${ }^{14} \mathrm{C}$ calibration, 7200-9439 BC. In Stuiver, M., Long, A. and Kra, R. S., eds., Calibration 1993. Radiocarbon 35(1): 125-135.

Merrill, R. T. and McElhinny, M. W. 1983 The Earth's Magnetic Field: Its History, Origin and Planetary Perspective. London, Academic Press: 401 p.

Neftel, A., Oeschger, H. and Suess, H. E. 1981 Secular non-random variations of cosmogenic carbon-14 in the terrestrial atmosphere. Earth and Planetary Science Letters 56: 127-147.

Pearson, G. W., Pilcher, J. R., Baillie, M. G. L., Corbett, D. M. and Qua, F. 1986 High-precision ${ }^{14} \mathrm{C}$ measurement of Irish oaks to show the natural ${ }^{14} \mathrm{C}$ variations from AD 1840 to 5210 BC. In Stuiver, M. and Kra, R. S., eds., Proceedings of the 12 th International ${ }^{14} \mathrm{C}$ Conference. Radiocarbon 28(2B): 911-934.

Pestiaux, A., Berger, A., Duplessy, J. C. 1987 Paleoclimatic variability at frequencies ranging from 1 cycle per 10000 years to 1 cycle per 1000 years: Evidence for nonlinear behaviour of the climate systems. Climate Change 12(1): 9-37.

Ribes, E., Merlin, Ph., Ribes, J.-C. and Barthalot, R. 1990 Absolute periodicities in the solar diameter derived from historical and modern data. Annales Geophysicae 7: 321-330.

Schove, D. J. 1955 The sunspot cycle, 649 BC to AD 2000. Journal of Geophysical Research 60: 127-145.

1981 Sunspot Cycles. Dowen, Hutchinson and Ross, Inc.: 397 p.

Sonett, C. P. and Finney, S. A. 1990 The spectrum of ra- diocarbon. Philosophical Transactions of the Royal Society of London A330: 413-426.

Sonett, C. P. and Suess, H. E. 1984 Correlation of bristlecone pine ring widths with atmospheric ${ }^{14} \mathrm{C}$ variations: A climate-Sun relation. Nature 307(5947): 141-143.

Stuiver, M. and Becker, B. 1986 High-precision decadal calibration of the radiocarbon time scale, AD 1950 2500 BC. In Stuiver, M. and Kra, R. S., eds., Proceedings of the 12th International ${ }^{14} \mathrm{C}$ Conference. Radiocarbon 28(2B): 863-910.

1993 High-precision decadal calibration of the radiocarbon time scale, AD 1950-6000 BC. In Stuiver, M. and Kra, R. S., eds., Calibration 1993. Radiocarbon 35(1): 35-65.

Stuiver, M. and Braziunas, T. F. 1993 Modeling atmospheric ${ }^{14} \mathrm{C}$ influences and ${ }^{14} \mathrm{C}$ ages of marine samples to 10,000 BC. In Stuiver, M. and Kra, R. S., eds., Calibration 1993. Radiocarbon 35(1): 137-189.

Stuiver, M. and Kra, R. S., eds., Proceedings of the 12th International ${ }^{14} \mathrm{C}$ Conference. Radiocarbon 28(2B): 8051030.

Stuiver, M., Pearson G. W. and Braziunas T. F. 1986 Radiocarbon age calibration of marine samples back to 9000 cal yr BP. In Stuiver, M. and Kra, R. S., eds., Proceedings of the 12 th International ${ }^{14} \mathrm{C}$ Conference. $R a$ diocarbon 28(2B): 980-1021.

Stuiver, M., and Reimer, P. J. 1993 Extended ${ }^{14} \mathrm{C}$ data base and revised CALIB $3.0{ }^{14} \mathrm{C}$ age calibration program. In Stuiver, M. and Kra, R. S., eds., Calibration 1993. Radiocarbon 35(1): 215-230.

Suess, H. E. 1965 Secular variations of cosmic ray produced carbon-14 in the atmosphere and their interpretations. Journal of Geophysical Research 70: 5937-5952. $1978 \mathrm{La}$ Jolla measurements of radiocarbon in tree-ring dated wood. Radiocarbon 20 (1): 1-18. 1980 The radiocarbon record in tree rings of the last 8000 years. In Stuiver, M. and Kra, R. S., eds., Proceedings of the 10 th International ${ }^{14} \mathrm{C}$ Conference. $R a$ diocarbon 22(2): 200-209.

Tarling, D. H. 1988 Secular variations of the geomagnetic field - archaeomagnetic record. In Stephenson, F. R. and Wolfendale, A. W., eds., Secular Solar and Geomagnetic Variations in the last 10,000 Years. Dordrecht, Kluwer Academic Publishers: 349-366.

Willis, E. H., Tauber, H. and Münnich, K. O. 1960 Variations in the atmospheric radiocarbon concentration over the past 1300 years. American Journal of Science Radiocarbon Supplement 2: 1-4.

$\mathrm{Xu}, \mathrm{Z} .1990$ Solar observations in ancient China and solar variability. Philosophical Transactions of the Royal Society of London A330: 513-515.

Zhou, W., An. Z., Lin, B., Xiao, J., Zhang, J., Xie, J., Zhou, M., Porter, S. C., Head, M. J. and Donahue, D. J. 1992 Chronology of the Baxie loess profile and the history of monsoon climates in China between 17,000 and 6000 years BP. In Long, A. and Kra, R. S., eds., Proceedings of the 14 th International ${ }^{14} \mathrm{C}$ Conference. Radiocarbon 34(3): 818-825. 